DENTAL FORUM

\title{
Knowledge, Attitude and Behaviour for Choosing Oral Hygiene Aids among Students of Management Institutes, Ghaziabad, India
}

S Kote, M Dadu, Sowmya AR, Aruna DS, D Arora

\begin{abstract}
Objective: There is a lot of information available about various oral hygiene aids used for the maintenance of oral hygiene and the prevention of oral diseases but the reason why people choose a particular product is under-reported. This study sought to assess the knowledge, attitudes and behaviour of choosing oral hygiene aids among students of management institutes in Ghaziabad, India. Method: A cross-sectional survey was conducted in five management institutes selected by simple random sampling and data were collected from 1224 students by self-administered structured validated questionnaire.

Results: The study showed that toothbrush (96.8\%) and toothpaste (95.2\%) were the main products used for the maintenance of oral hygiene. The most commonly used brand dentifrices were Colgate and Close-Up (47\%, 23.3\%) and in toothbrush, Oral B and Colgate $(48.4 \%, 30.9 \%)$, respectively. A particular brand of toothpaste was preferred by $66.4 \%$ of the subjects because of childhood and parental use, which was the most influential factor (56.9\%). Bristle design was the main criterion for choosing a toothbrush (44.9\%), followed by bristle consistency (33.1\%). The most commonly used toothbrushes were of soft bristle consistency (51.2\%) and 10.9\% of the subjects did not know the type of bristle consistency present in their toothbrush.

Conclusion: Selection of oral hygiene products was based more on parental influence and there seems to be a lack of knowledge and awareness about how to choose a dentifrice and toothbrush.
\end{abstract}

Keywords: Attitude, behaviour, knowledge, management, oral hygiene aids, students

\section{Conocimientos, Actitudes y Comportamientos para Elegir Elementos Auxiliares la Higiene Oral entre los Estudiantes de los Institutos de Administración, Ghaziabad, India}

\author{
S Kote, M Dadu, Sowmya AR, Aruna DS, D Arora
}

\begin{abstract}
RESUMEN
Objetivo: Hay mucha información disponible sobre diferentes elementos auxiliares usados para el mantenimiento de la higiene oral y la prevención de enfermedades orales, pero las razones por las cuales la gente elige tal o cual producto en particular, no son reportadas en la misma medida. Este estudio buscó evaluar los conocimientos, actitudes y comportamientos a la hora de elegir los elementos auxiliares para la higiene bucodental entre los estudiantes de los institutos de administración en Ghaziabad, India.

Método: Se realizó una encuesta transversal en cinco institutos de administración seleccionados por muestreo aleatorio simple, y se obtuvieron datos de 1224 estudiantes mediante un cuestionario validado estructurado auto-administrado.
\end{abstract}

From: Department of Public Health Dentistry, ITS - Centre for Dental Studies and Research, Muradnagar, Ghaziabad, Uttar Pradesh, India.
Correspondence: Dr S Kote, Room No. 5, Department of Public Health Dentistry, ITS - Centre for Dental Studies and Research, Muradnagar, Ghaziabad 201206, Uttar Pradesh, India. E-mail: sunder_kote2000@ yahoo.com 
Resultados: El estudio mostró que el cepillo de dientes (96.8\%) y la pasta de dientes (95.2\%) eran los principales productos utilizados para el mantenimiento de la higiene oral. Las marcas dentífricas más comúnmente utilizadas fueron Colgate y Close-Up (47\%, 23.3\%), y en los cepillos de dientes, Oral B y Colgate $(48.4 \%, 30.9 \%)$ respectivamente. Una marca particular de pasta de dientes era preferida por $66.4 \%$ de los sujetos debido al uso por parte de padres y niños, lo que resultó ser el factor más influyente (56.9\%). El diseño de las cerdas fue el principal criterio para elegir un cepillo de dientes (44.9\%), seguido por la consistencia de las cerdas (33.1\%). Los cepillos de dientes más comúnmente usados fueron los de cerdas de consistencia suave (51.2\%) y $10.9 \%$ de los sujetos no sabian el tipo de consistencia de las cerdas de su cepillo de dientes.

Conclusión: La selección de productos de higiene oral se basaba más en la influencia de los padres, y parece que hay una falta de conocimiento y conciencia sobre cómo elegir el dentifrico y el cepillo de dientes.

Palabras claves: Actitud, comportamiento, conocimiento, administración, auxiliares de la higiene oral, estudiantes

West Indian Med J 2013; 62 (8): 759

\section{INTRODUCTION}

Prevention of oral disease is considered to be the most effective, acceptable and efficient method to attain oral health. Dental health education has been largely aimed at children and adolescents as priority. The attitude of people toward their own teeth, and the attitude of dentists who provide dental care, play an important role in determining the oral health condition of the population (1).

The best way to maintain good oral hygiene for good health of oral tissues is by "plaque control" since plaque is the main factor responsible for dental and gingival diseases. Toothbrush and toothpaste are the most widely used oral hygiene aids.

Factors like education, income, information from media (advertisements) and personal choices like taste/ flavour, colour and appearance have an effect on choosing an oral hygiene product. Previous studies have shown that mass media, dental professionals and dental literature are the main sources of oral health information (2).

There is a lot of information available about various oral hygiene aids used for the maintenance of oral hygiene but the reason why people use a particular product is not addressed. The present study was conducted to assess the knowledge, attitudes and behaviour of students of management institutes in Ghaziabad (India) for choosing oral hygiene aids.

\section{SUBJECTS AND METHOD}

A cross-sectional survey was conducted in five management institutes selected by simple random sampling from 25 management institutes in Ghaziabad district, India. Ethical clearance was obtained from the ethics committee of ITS College for Dental Studies and Research Centre, Muradnagar, Ghaziabad. Permission from the Directors of the management institutes selected for the study was given. A written informed consent was obtained from all students who were willing to participate in the study.

\section{Study proforma}

Data were collected using a self-administered pretested, structured, closed-ended questionnaire containing questions for knowledge, attitudes and behaviour of students in selecting oral hygiene products.

A total of 1224 (male - 844, female - 380) students participated in the study with mean age 20.56 years. The survey was conducted over a period of three months from July 1, 2011 to September 31, 2011. Before starting the survey, the class teachers instructed the students to cooperate in the study. All the management students who were present on the day of survey and gave consent were included in the study. The investigator explained the study purpose and all questions were explained in detail to avoid any ambiguity and to clarify any doubts with the investigator, in relation to any question prior to answering. Students were assured that their answers would be kept confidential and would not be considered for their academic record. The investigator requested all the students to answer promptly on the pretested, structured, close-ended questionnaire forms without discussing or copying from one another.

Instructions given before filling out the questionnaire were:

* Answer all the questions.

* Choose any one answer for each question.

* If more than one answer is given by the student for the same question, that particular question would not be considered in the study.

* To avoid discussing and copying, 15 minutes time was given to read the questions and fill in all the answers.

* After 15 minutes, the investigator collected all the proformas distributed and checked the answers given by the students and later uploaded them in the computer for analysis.

The analysis was performed using the SPSS software (version 18; SPSS, Chicago, IL, USA). The frequency of dis- 
tribution was calculated followed by the percentage. Microsoft Excel was used to generate graphs.

\section{RESULTS}

Of the 1224 students (mean age $20.56 \pm 2.17$ years) who participated in the survey, $844(69.0 \%)$ were males and 380 $(31.0 \%)$ were females. Results of the study showed that toothbrush and toothpaste were the main products used for cleaning teeth, $96.8 \%$ were toothbrush users, toothpaste was used by $95.2 \%$ of the subjects and $2.0 \%$ used neem datun/salt as a teeth cleaning material (Fig. 1).

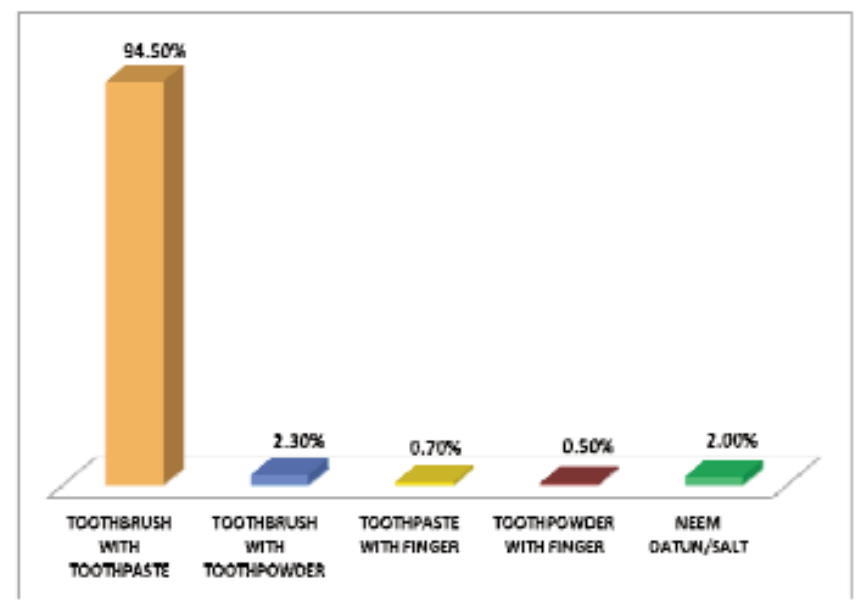

Fig. 1: Oral hygiene products used by the subjects.

Regarding the consistency of toothbrush bristles, more than half of the students preferred soft bristles $(51.2 \%)$, followed by medium bristles (34.6\%) and hard bristles $(3.3 \%) ; 10.9 \%$ of the students did not know the consistency of toothbrush bristles (Fig. 2). Only $45.9 \%$ of the subjects

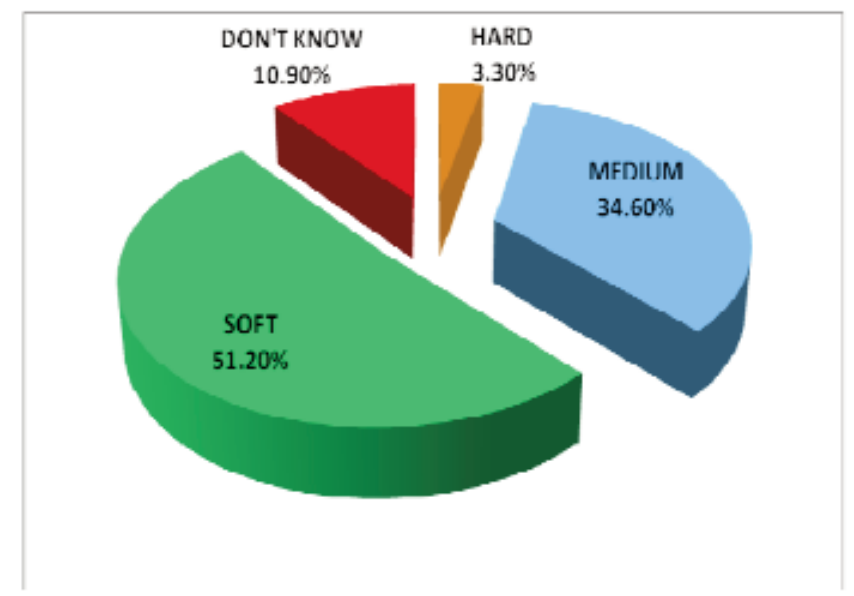

Fig. 2: Consistency of the bristles in toothbrush used.

knew that the type of toothbrush bristle was written on the box of the toothbrush; $38.3 \%$ knew from their dentist and $15.8 \%$ asked the shopkeeper (Fig. 3).
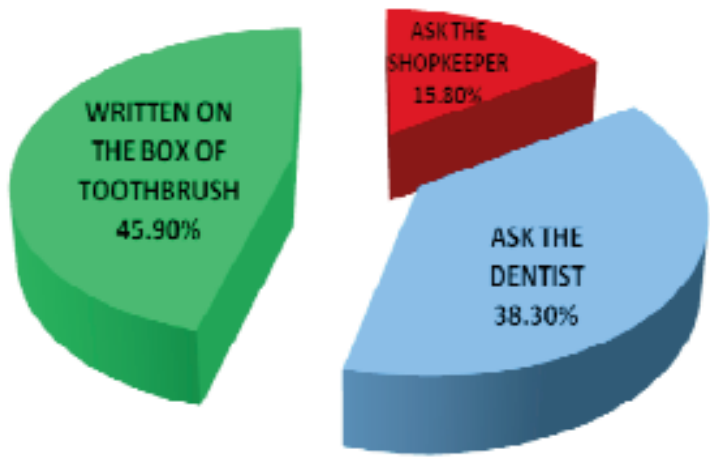

Fig. 3: How subjects get to know about type of bristle present in the toothbrush while buying.

In relation to frequency of change of toothbrush, $37.5 \%$ of the subjects changed their toothbrush once per month, followed by $42.6 \%$ in three months and $19.9 \%$ in six months (Fig. 4).

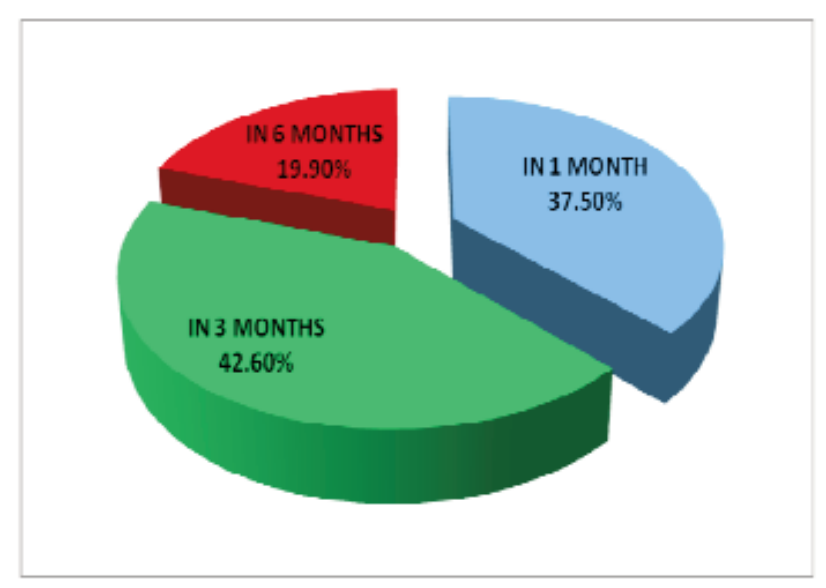

Fig. 4: Frequency of changing toothbrush.

The most commonly used brand of toothbrush was Oral B $(48.40 \%)$ followed by Colgate $(30.90 \%)$. The percentage of the population unaware of the brand of the toothbrush was $3.6 \%$.

Bristle design (zig-zag, flat, cross-action) was the most influential factor in selection of a toothbrush (44.90\%) followed by bristle consistency (33.10\%). The percentage of people selecting their toothbrushes after seeing the advertisements on the television, in newspapers, cinema halls or hearing the advertisements on the radio was $3.90 \%$, whereas $2.30 \%$ of the subjects chose any toothbrush available in the shop. Only $2.90 \%$ of subjects selected their toothbrush based on cost and $3.30 \%$ of the students selected their toothbrush according to the advice of peers. Approximately ten per cent $(9.60 \%)$ selected their toothbrush according to the dentist's advice (Fig. 5). 


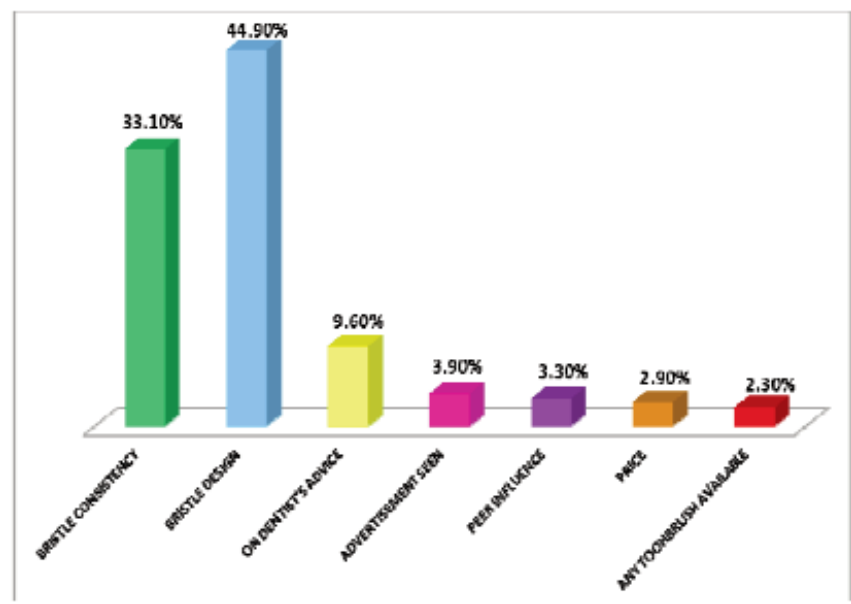

Fig. 5: Influential factors in selection of a toothbrush.

The most commonly used brand of dentifrice was Colgate $(47.00 \%)$ followed by Close Up $(23.3 \%)$ and Pepsodent $(18.90 \%)$. While selecting different brands of dentifrice, the most influential factor was parents $(56.90 \%)$, followed by dentist (18.9\%) and advertisement/celebrity [17.60\%] (Fig. 6); 66.4\% of subjects used the same brand of dentifrice since their childhood.

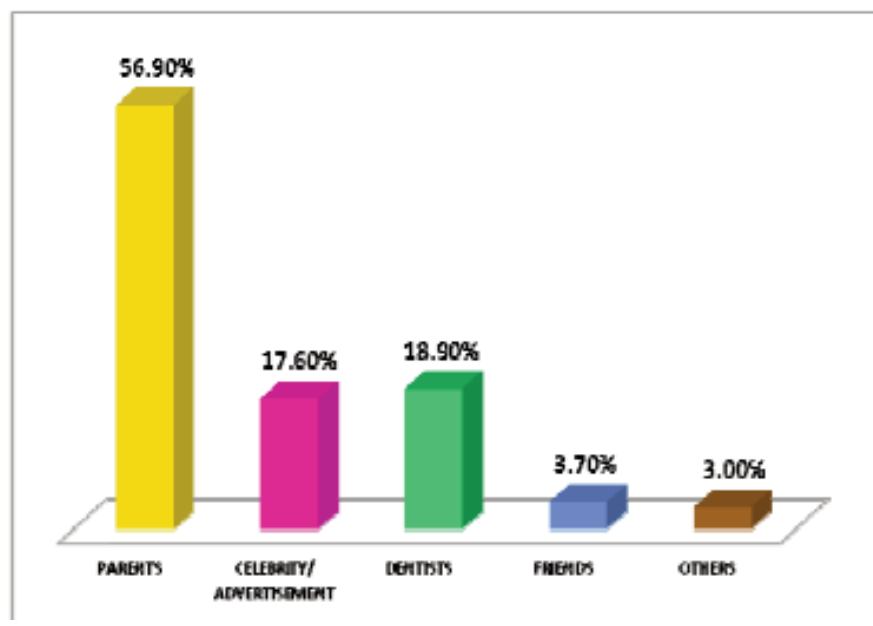

Fig. 6: Influential factors in selection of dentifrice.

The reasons given for buying dentifrice were: to maintain healthy teeth and gums (47.3\%), to maintain long lasting freshness $(27.9 \%)$, routine procedure of teeth cleaning $(15.4 \%)$, prevention of tooth decay $(5.9 \%)$ and for whitening of tooth (3.6\%) [Fig. 7].

The main reason for choosing the dentifrice was dentist's advice (30.6\%), followed by flavour/smell of toothpaste (29.5\%), colour (16.6\%), family/friend's choice $(10.7 \%)$, and advertisement (7.4\%). Cost was the least important criterion (5.2\%) [Fig. 8].

The majority of the subjects (70.1\%) used mouthwash, but only $23.5 \%$ stated that it was to maintain healthy gums; $64.3 \%$ used it to maintain long lasting freshness, $9.2 \%$ for

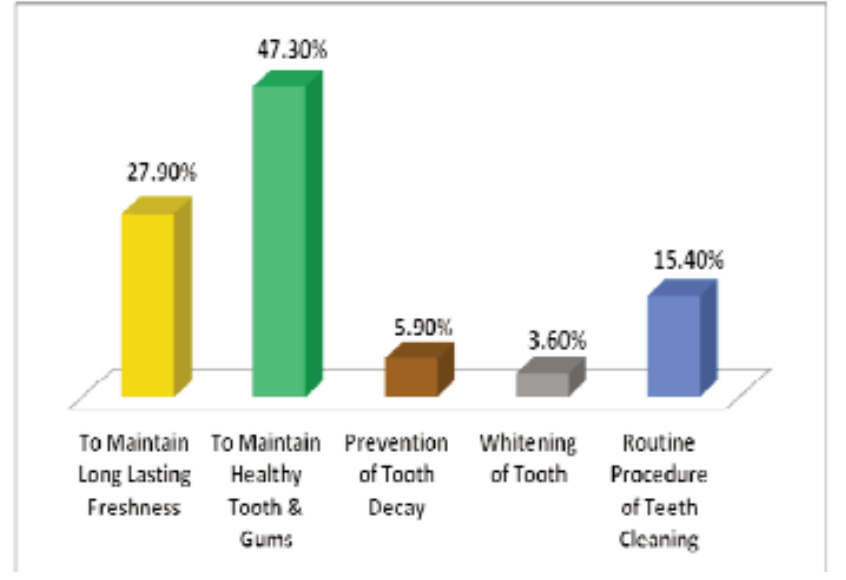

Fig. 7: Reason for buying toothpaste/toothpowder.

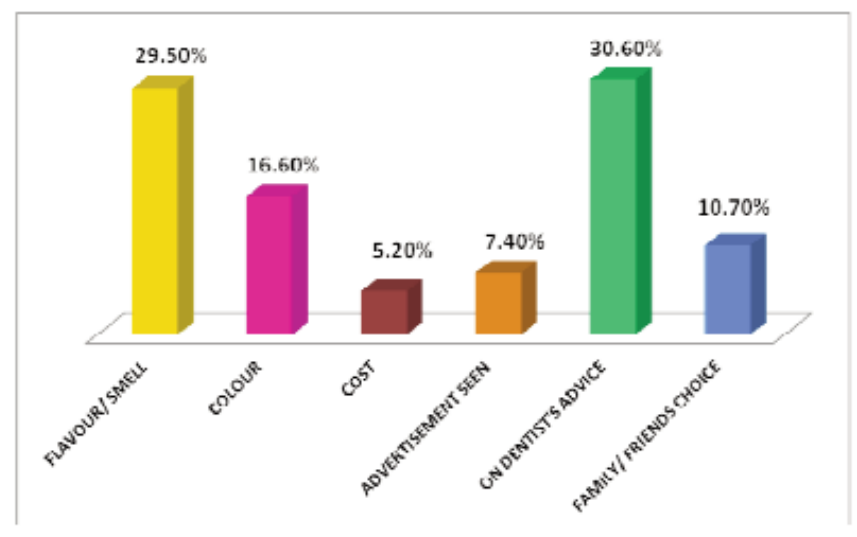

Fig. 8: Criteria for choosing the dentifrice.

prevention of tooth decay and 3.0\% was influenced by friends or family members (Fig. 9). Criteria for selection of mouthwash was flavour/smell/colour (45.1\%), followed by dentist's advice (30.5\%), advertisement (11.7\%), cost (6.7\%) and family/friend's advice (6.0\%) [Fig. 10].

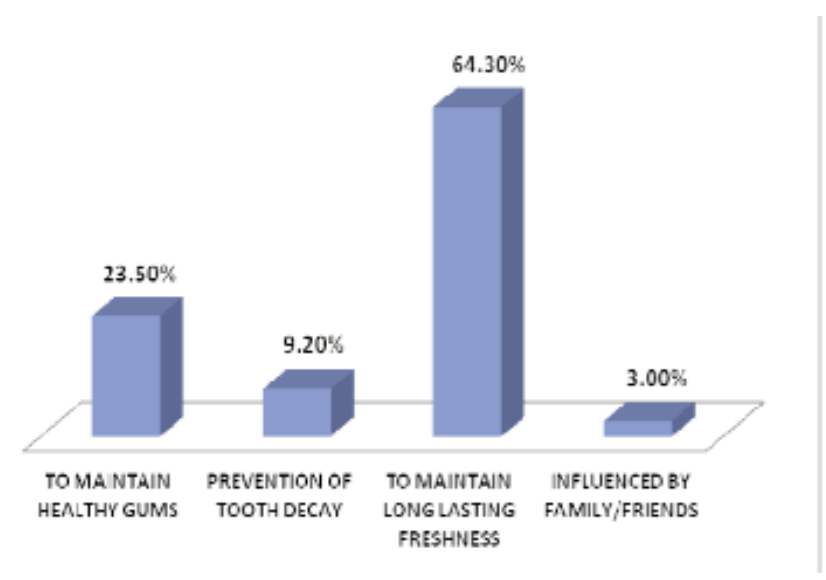

Fig. 9: Reason for using mouthwash. 


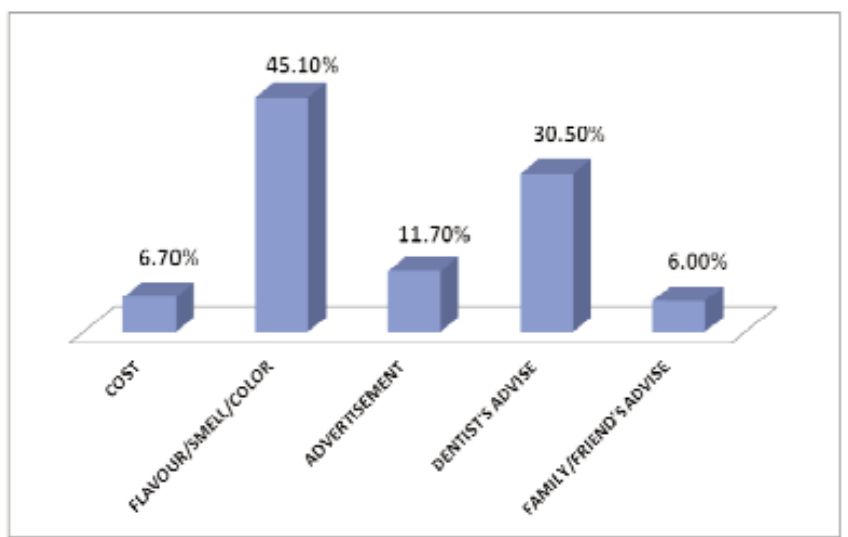

Fig. 10: Criteria for selection of mouthwash.

Other additional oral hygiene aids were used by $43.6 \%$ of the subjects. Toothpicks $(64.10 \%)$ were the most commonly used products, followed by inter-dental brush $(22.1 \%)$ and dental floss (10.8\%) [Fig. 11].

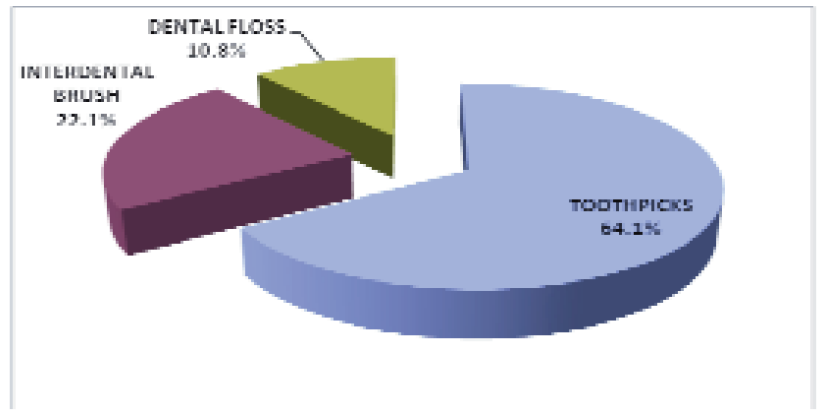

Fig. 11: Additional other oral hygiene aids used (among the users).

The reason for choosing other additional oral hygiene aids was dentist's advice (38.7\%), to clean food lodgement in inter-dental area (33.7\%) and $27.6 \%$ was using other additional oral hygiene aids as routine procedure for teeth-cleaning (Fig. 12).

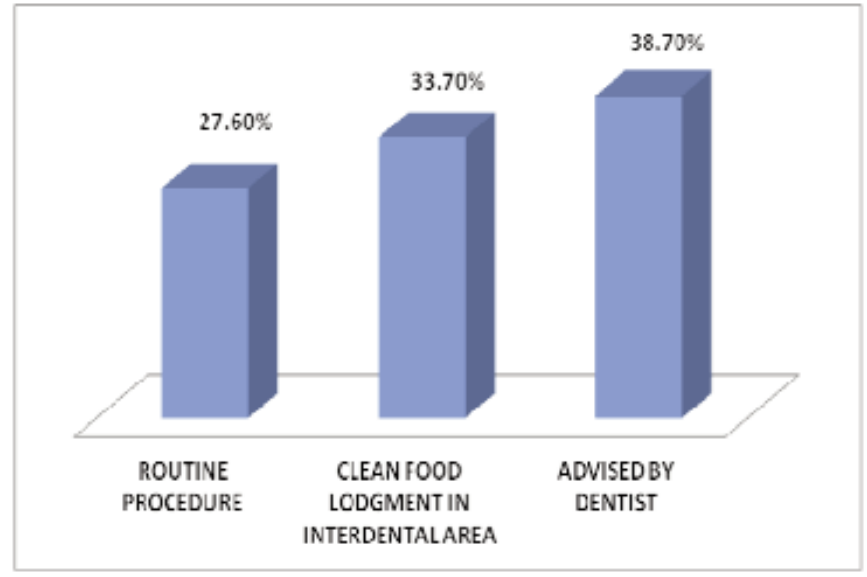

Fig. 12: Reason for using other additional oral hygiene aids.
The selection of other oral hygiene aids was based on dentist's advice $(52.2 \%)$, followed by family or peer advice (25.6\%) and advertisement (22.2\%) [Fig. 13].

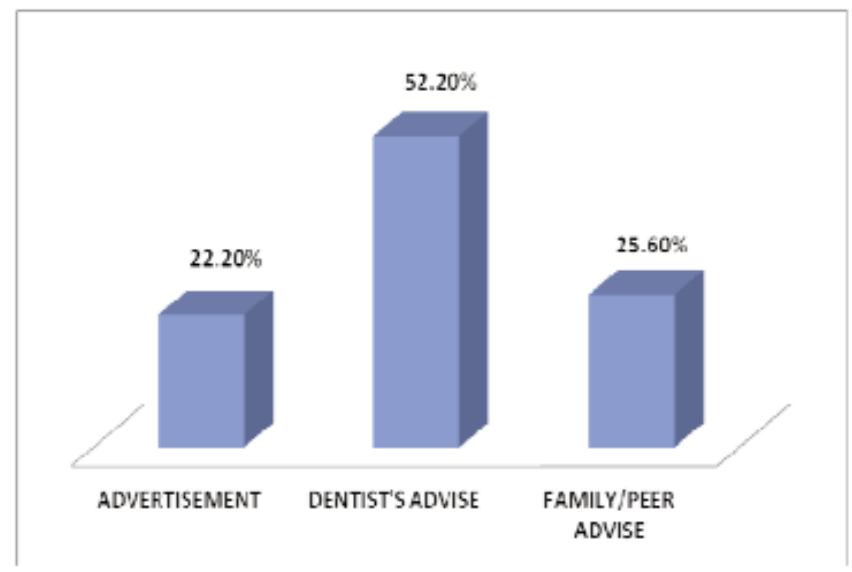

Fig. 13: Criteria for selection of other additional oral hygiene aids.

\section{DISCUSSION}

Oral hygiene practices in India are heavily based on tradition and culture with use of indigenous substances being widely prevalent. The present study was conducted among students of the management institutes who are part of the urban population, where most of the people are educated and hence, toothbrush and toothpaste use was expected to be more.

Toothbrush and dentifrice were the main products used for the maintenance of oral hygiene among the population. The percentage of toothbrush use was $96.8 \%$ compared to $97.6 \%$ for secondary school students in a study done by Lian et al (3) and $100 \%$ for secondary school students in Nepal (4). The percentage of toothbrush use was found to be more compared to the urban population (94.4\%) of Udaipur (5), of teachers $[76.7 \%]$ (6), of caregivers $(93.0 \%)$ in daycare centres (7), of consumers [80\%] (8) and of nursing students [77.7\%] (9) in Bangalore.

In the present study, toothpaste use was found to be $95.2 \%$, supported by other studies such as $93.0 \%$ for caregivers in daycare centres (7), $90.6 \%$ of an urban population (5) and $100 \%$ of secondary school students in Nepal (4). Toothbrush and toothpaste use is the most effective way of cleaning teeth and maintaining oral hygiene.

In the present study, the percentage of people using soft bristle toothbrush was high compared to medium and hard bristle brush users $(51.2 \%, 34.6 \%$ and $3.3 \%$, respectively), similar to studies done by Sharda $[59.6 \%$ soft, $17.0 \%$ medium] (5) and Neamatollahi [17.9\% soft, $48.1 \%$ medium, $8.7 \%$ hard] (10). One-tenth $(10.9 \%)$ of the subjects did not know the type of bristles present in their toothbrush, higher than the $4.6 \%$ in the study by Sharda (5) and less than the $25.3 \%$ in the study done by Neamatollahi and Ebrahimi (10). Though the effect of the bristle consistency on the efficiency 
of cleaning has not been proven, soft bristle brushes are likely to cause less damage to the tooth structure and the gums (gingiva). For optimal oral health, the American Dental Association (ADA) and US Surgeon General recommend that individuals brush twice and floss at least once a day and have regular prophylactic dental visits.

In the present study, $42.6 \%$ of people changed their toothbrush in three months followed by $37.5 \%$ in one month and $19.9 \%$ in six months, which is similar to previous studies $(5,10)$. A toothbrush with frayed bristles might be less effective in plaque bio-film removal and harmful to the tooth structure.

Previous studies have shown that mass media, dental professionals and dental literature are the main sources of oral health information (5). In the present study, $56.9 \%$ of the population selected their toothpaste by parental influence, $30.6 \%$ by dentist's advice, $29.5 \%$ by flavour and $21.8 \%$ by cost, colour and foaming action of the toothpaste. Only $7.5 \%$ of the subjects chose their toothpaste by media influence, in contrast to another study (5) in which $39.6 \%$ of subjects choose their toothpaste by media influence, $16.0 \%$ by brand, $16.0 \%$ by flavour, $4.8 \%$ on dentist's advice and $6.0 \%$ by parental influence. Parental influence in this study (56.9\%) was in agreement with the study done by Al-Omiri et al (11) and Vani et al (8) [59.0\% and 40.0\%, respectively].

Colgate dentifrice is the most purchased brand (47\%) in the present study which was also the most purchased dentifrice in the study done by Sharda [36.2\%] (5).

For selection of toothbrush, fewer people $(9.6 \%)$ did so on the advice of dental professionals, similar to a previous study [7\%] (5). Toothbrush selection was based more on bristle design (zig-zag, flat, cross-action) and bristle consistency.

The dental professionals are unable to take much time out of their busy schedules to give information to the people about the oral hygiene aids available and method of cleaning. Because people are not availing themselves to the dental healthcare facilities, a lower percentage of persons choose their oral hygiene aids upon the advice of the dental professionals.

The effect of parental influence on choosing oral hygiene aids seems to be strong in the present study. Therefore, dental professionals need to work more effectively with the manufacturers and advertisers to support the dissemination of helpful information and facts about the oral hygiene products through the management personnel of private companies.

The use of other oral hygiene aids like dental floss, toothpicks and mouthwashes helps in keeping good oral hygiene and maintaining the health of the oral cavity.

In the present study, $70.1 \%$ of persons used mouthwash, similar to a study by Al-Shammari et al (12); $11.8 \%$ of respondents used dental floss. Zhu et al (13) in their study showed use of dental floss by $4.1 \%$ and regular use of tooth- picks after meals by $36 \%$ of the respondents. Overall, the percentage of people using other oral hygiene aids was low $(7.8 \%)$ and the selection of these aids was mainly based on the dental professional's advice. Dental professionals should spend more time making people aware of the different oral hygiene aids available, how to use these aids and the importance of their uses.

\section{CONCLUSION}

In summary, selection of oral hygiene products was based more on parental influence. There seems to be a lack of knowledge and awareness about how to choose a dentifrice and toothbrush, so education of people on the importance of oral hygiene maintenance, proper selection and method of use of oral hygiene products is needed.

\section{ACKNOWLEDGEMENTS}

The authors wish to thank the Directors of the management institutes for their full support and cooperation in the study.

\section{REFERENCES}

1. Dagli RJ, Tadakamadla S, Dhanni C, Duraiswamy P, Kulkarni S. Self reported dental health attitude and behaviour of dental students in India. J Oral Sci 2008; 50: 267-72.

2. Paik DI, Monn HS, Horowitz AM, Gitt HC, Jeong KL, Suh SS. Knowledge of oral practices related to caries prevention among Koreans. J Public Health Dent 1994; 54: 205-10.

3. Lian CW, Phing TS, Chat CS, Shin BC, Baharuddin LH, Jalil ZB et al. Oral health knowledge, attitude and practice among secondary school students in Kucing, Sarawak. Arch Orofac Sci 2010; 5: 9-16.

4. Humagain M. Evaluation of knowledge, attitude and practice (KAP) about oral health among secondary level students of rural Nepal - a questionnaire study. WebmedCentral Dentistry 2011; 2: 1-11.

5. Sharda A, Sharda J. Factors influencing choice of oral hygiene products used among the population of Udaipur, India. Int J Dent Clin 2010; 2: $7-12$.

6. Shanthi M, Hiremath SS. Knowledge and attitude about dental diseases and their prevention among primary and middle school teachers in urban and rural areas of Bangalore District. J Ind Assoc Pub Health Dent 2011; 2011 (Suppl 1): 692-5

7. Vinay S, Naveen N, Naganandini N, Devi MA. Oral health knowledge, attitude and practices of caretakers in baby day care centres of Bangalore city. J Ind Assoc Pub Health Dent 2011; 17 (Suppl 1): 233-6.

8. Vani G, Babu MG, Panchanatham N. Toothpaste brands - a study of consumer behaviour in Bangalore city. J Econ Behav Stud 2010; 1: 27-39.

9. Senthil M, Bhat PK. Oral health knowledge and attitude among final year nursing undergraduate students in Bangalore city, India. J Ind Assoc Pub Health Dent 2011; 17 (Suppl 1): 389-96.

10. Neamatollahi H, Ebrahimi M. Oral health behavior and its determinants in a group of Iranian students. Indian J Dent Res 2010; 21: 84-8.

11. Al-Omiri MK, Al-Wahadni AM, Saeed KN. Oral health attitudes, knowledge, and behavior among school children in North Jordan. J Dent Educ 2006; 70: 179-87.

12. Al-Shammari KF, Al-Ansari JM, Al-Khabbaz AK, Dashti A, Honkala EJ. Self-reported oral hygiene habits and oral health problems of Kuwaiti adults. Med Princ Pract 2007; 16: 15-21.

13. Zhu L, Petersen PE, Wang HY, Bian JY, Zhang BX. Oral health knowledge, attitudes and behavior of adults in China. Int Dent J 2005; 55: $231-41$ 